\title{
Association of mitochondrial variants A4336G of the tRNAGln gene and 8701G/A of the MT-ATP6 gene in Mexicans Mestizos with Parkinson disease
}

 \\ Martha Patricia Gallegos-Arreola ${ }^{4}$, Sofía Lizeth Alcaraz-Estrada ${ }^{1}$, Leticia Cortes-Espinosa ${ }^{1}$, Carlos Palma Flores ${ }^{5,6}$, \\ Patricia Canto7, Ramón Mauricio Coral Vázquez ${ }^{6,8}$ \\ ${ }^{1}$ Centro Médico Nacional "20 de Noviembre”, Instituto de Seguridad y Servicios Sociales de los Trabajadores del Estado, Ciudad \\ de México, México, ${ }^{2}$ Instituto de Ciencias Médicas y de la Nutrición Salvador Zubirán, Ciudad de México, Mexico, ${ }^{3}$ Centro Médico \\ Nacional Siglo XXI, Instituto Mexicano del Seguro Social, Ciudad de México, Mexico, ${ }^{4}$ Centro de Investigación Biomédica \\ de Occidente, Jalisco, Mexico, ${ }^{5}$ Catedrático CONACYT, Sección de Estudios de Posgrado e Investigación, Escuela Superior de Medicina, \\ Instituto Politécnico Nacional, Ciudad de México, México, ${ }^{6}$ Subdirección de Enseñanza e Investigación, Centro Médico Nacional \\ "20 de Noviembre", Instituto de Seguridad y Servicios Sociales de los Trabajadores del Estado, Ciudad de México, México, \\ ${ }^{7}$ Unidad de Investigación en Obesidad, Facultad de Medicina, Universidad Nacional Autónoma de México, Ciudad de México, \\ México, ${ }^{8}$ Sección de Estudios de Posgrado e Investigación, Escuela Superior de Medicina, Instituto Politécnico Nacional, Ciudad \\ de México, México
}

\begin{abstract}
Introduction: Sporadic Parkinson's disease (PD) is a neurodegenerative disorder of unknown etiology. In recent years, it has been established that a genetic component underlies different forms of the disease. For instance, mitochondrial genome variants have been implicated in the pathogenesis of the PD.

Aim of the study: To determine the association of tRNA(Gln) 4336 and 8701A>G (ATP6: Thr59Ala) mitochondrial DNA polymorphisms with the presence of PD in Mexican mestizo patients.

Material and methods: This was a cross-sectional study in which patients were recruited from four tertiary-care level hospitals in Mexico. Genotyping was performed using real-time PCR with TaqMan genotyping assays. Genotypes were confirmed by automated sequencing.

Results: The 4336C allele of the tRNAGln gene was present at a low frequency, and the 8701G allele of the MT-ATP6 gene was not associated with PD.

Conclusions: The 4336C variant of the tRNAGln gene was uncommon in the study population, and 8701A/G of MT-ATP6 was not associated with PD in Mexican Mestizos.
\end{abstract}

Key words: Parkinson's disease, association, variants tRNAGln, MT-ATP6, genes.

Communicating authors

Silvia García, MSc, Servicio de Investigación Clínica, Centro Médico Nacional "20 de Noviembre”, Instituto de Seguridad y Servicios Sociales de los Trabajadores del Estado, San Lorenzo 502, C.P. 03100, Ciudad de México, México, phone: 01525552005003 , fax: 015233363262 00, e-mail: rolasil@yahoo.com.mx

Ramón M. Coral-Vázquez, PhD, Sección de Estudios de Posgrado e Investigación, Escuela Superior de Medicina del Instituto Politécnico Nacional, Plan de San Luis y Díaz Mirón s/n, Col. Casco de Santo Tomas, C.P. 11340, Ciudad de México, México, phone: (5255) 57296300, ext. 62820, fax: (5255) 57296300, ext.62820, e-mail: rmcoralv@gmail.com, rcoral@ipn.mx 


\section{Introduction}

Idiopathic Parkinson's disease (PD) is a chronic progressive neurodegenerative disease that affects $1-2 \%$ of the population that is over 65 years old [14]. Parkinson's disease reduces the quality of life and autonomy of patients [16,31]. Genetic factors confer susceptibility to PD, and genetic variants of mitochondrial and nuclear genomes are involved in this disease $[18,24,36]$.

Studies in Italian and US populations suggest that some mitochondrial DNA haplogroups may cause a lower risk for PD, which supports that the mitochondrial oxidative phosphorylation pathway is involved in the susceptibility to idiopathic PD $[23,37]$. Analysis of cybrids [11] and studies on postmortem substantia nigra tissue [32] from PD patients has shown that there is a defect in complex I activity, indicating that alterations in the mitochondrial DNA may participate in dysfunction of the mitochondria.

It has also been reported that an $A>G$ variation of the mitochondrial tRNAGIn gene (at position 4336) occurs at an increased frequency in Caucasian persons who died of Alzheimer's disease and PD [6].

Additionally, a study in the Spanish population found an association between the tRNAGln 4336 mitochondrial DNA variant and PD [25]. However, other studies did not corroborate this association in different populations $[1,9,23,35]$.

Furthermore, 8701A/G mtSNP changes a threonine to an alanine at ATPase6. This protein forms part (as a subunit) of a large enzyme called ATP synthase [38]. Kazuno et al. [17] proposed that mtDNA polymorphisms $8701 \mathrm{~A} / 10398 \mathrm{~A}$ play a role in the pathophysiology of PD by affecting the mitochondrial matrix $\mathrm{pH}$ and intracellular calcium dynamics.

Establishing the pathogenicity of mtDNA or identifying causal/functional variants remains an important challenge [2], and its pathological associations with PD can be influenced by the genetic background of the investigated population. It is known that the Mexican population was a result of genetic admixture among Amerindians, Caucasian and, to a lesser extent, Africans [29] and, as in other Latin American populations [2], the genetic factors that predispose Mexican Mestizos to PD remain mostly unknown $[22,28,39]$. Therefore, this study aimed to evaluate the association of variants (nt) 4336 of tRNAGln gene and $8701 \mathrm{~A} / \mathrm{G}$ of mtATP6 within PD Mexicans Mestizos patients.

\section{Material and methods Study population}

The study was approved by the Human Research Committees of the participating institutions, and informed written consent was obtained from all individuals. This was a cross-sectional study in which 175 PD patients were (consecutively) recruited from four tertiary-care level hospitals in Mexico (Centro Médico Nacional "20 de Noviembre"-ISSSTE, Centro Médico Nacional Siglo XXI-IMSS, Instituto de Ciencias Médicas y de la Nutrición "Salvador Zubirán", Mexico City; and División de Genética, Centro de Investigación Biomédica de Occidente-IMSS, Jalisco, Mexico). The PD diagnoses were performed by an experienced neurologist. The diagnoses were based on the Queen Square Brain Bank criteria [15]. Controls included 194 healthy individuals without a family history of PD, or other neurological diseases. Individuals (of both groups) were of Mexican mestizo ethnic origin. Secondary Parkinsonism cases were excluded.

\section{DNA isolation and genotyping}

Peripheral blood samples were obtained from patients and controls. Genomics DNA was isolated using the CTAB-DTAB method [12]. Genotyping was performed by real-time PCR using TaqMan specific probes (hydrolysis probes). Probes were designed for 4336T/C variant of the tRNAGln gene: TTCGATTCTCAT[A]GTCCTAG-VIC (for wild variant) and CGATTCTCAT[G]GTCCTAG-FAM (for mutant variant); and for $8701 \mathrm{~A} / \mathrm{G}$ variant of the mtATP6 gene: F-CCGACTAATCACCACCCAAC and R-TCGTCCTTTAGTGTTGTGTATGG. Real-time PCR was performed on a LightCycler 480 II (Roche Diagnostics GmbH, Switzerland). PCR reactions were prepared according to the manufacturer's instructions.

\section{Statistical analysis}

Demographic and clinical variables between PD patients and controls groups were analyzed using SPSS v.16.0 (SPSS Inc, Chicago, IL). Numeric variables that are not normally distributed are presented as median and range and were compared using the Mann-Whitney $U$ test. Comparisons were made between categorical variables. Normally distributed numeric variables are presented as mean $\pm S D$ and analyzed using the Student $t$-test. 


\section{Results}

We analyzed two polymorphisms in 194 healthy individuals and 175 PD patients. In the PD group, 75 females and 100 males were recruited and for the control group, 123 females and 171 males were recruited. One hundred and thirty-one individuals were documented as coffee consumers; of which, 3 belonged to the group of PD patients and 23 were in the control group $(\mathrm{OR}=0.41,95 \% \mathrm{Cl}: 0.18-0.90$, $p$ < 0.02). Tobacco use was documented in 71/175 PD patients and in 76/194 controls subjects $(O R=1.06$, 95\% Cl: 0.69-1.6, $p<0.7$ ) (Table I).

Allele frequencies of the tRNAGln T4336C and ATP6 G8701A mitochondrial DNA polymorphisms are presented in Table II. Three hundred sixty-nine individuals were genotyped for the T433C variant of mtDNA (194 controls and 175 with PD). Polymorphism C was not present in any of the controls, and only in $1 / 175$ patients (OR $=3.402,95 \% \mathrm{Cl}$ : $0.13-$ 84.07, $p=0.27$ ).

Three hundred sixty-five individuals were genotyped for the G8701A mtDNA polymorphism; 211 of them were controls and 154 were PD patients. The $G$ allele was present in 151/211 controls and in 120/154 PD (OR = 0.713, 95\% Cl: 0.43-1.15, $p=0.84)$ (Table II).

\section{Discussion}

Parkinson's disease is a complex, chronic neurological disorder for which aging is the most critical risk factor. Both in PE and aging, a decrease in the activity of complexes I and IV, an increase in mtDNA deletions, swelling of neuronal mitochondria and reduced $\mathrm{PGC}-1 \gamma$ activity have been documented $[5,20,27]$. About half of people over 85 years have mild parkinsonian signs, and their brains show pathological changes in the SNpc, similar to patients with PD [3].

Maternally inherited mitochondrial DNA (mtDNA) codes for 13 protein subunits in the respiratory chain
Table I. Demographic and clinic characteristics of patients with Parkinson's disease (PD) and healthy controls

\begin{tabular}{|lccc|}
\hline Variable & $\begin{array}{c}\text { PD } \\
(n=175)\end{array}$ & $\begin{array}{c}\text { Controls } \\
(n=194)\end{array}$ & P value \\
\hline $\begin{array}{l}\text { Mean age } \\
\text { (years) }\end{array}$ & $62.97 \pm 10.96$ & $68.48 \pm 6.04$ & 0.01 \\
\hline Male/Female & $100 / 75$ & $71 / 123$ & 0.0001 \\
\hline $\begin{array}{l}\text { Coffee } \\
\text { consumers }\end{array}$ & $3 / 58$ & $23 / 63$ & 0.02 \\
\hline Tobacco users & $71 / 175$ & $76 / 194$ & 0.7 \\
\hline
\end{tabular}

[21]. This mtDNA has a high number of copies per cell and has a high mutation rate. Interestingly, it has been observed that mtDNA mutations accumulate throughout PD, and the amount of mutations seem to correlate with the severity and burden of the disease in a rat model [26]. Likewise, it has been proposed that selective mtDNA damage may be a possible molecular marker of vulnerable nigral neurons in PD [30]. These somatic mutations in mtDNA may contribute to the progression of the disease due to the dysfunction of the electron transport chain [19].

Mitochondrial tRNA genes are hot-spots for pathological mutations and concentrate more than half of all mtDNA mutations [10]. More than 200 mt-tRNA mutations have been linked to various pathological states [13], these can have detrimental effects on mitochondrial functioning because they are closely related in protein synthesis.

The association of the tRNAGIn variant T4336C with PD development has been inconsistent. Egensperger et al. [6] evaluated mutations of mtDNA T4336C in patients with PD with Lewy bodies and found that it was present in 2 of 23 patients, and none of the 100 controls. Similar results were reported in a Caucasian population and [25] in a Hispanic population. In contrast, Swerdlow et al. [34] in a Central Virginia population (USA), did not find this mutation in 100 PD patients, but it was detected in 4 of 106 controls. In fact, the variant showed

Table II. Association of mitochondrial polymorphisms with Parkinson's disease

\begin{tabular}{|c|c|c|c|c|c|c|}
\hline Polymorphisms & Allele & Patients & Controls & OR & $95 \% \mathrm{Cl}$ & $P$ value \\
\hline \multirow[t]{2}{*}{ tRNAGIn T4336C } & C & 1 & 0 & \multirow{2}{*}{3.402} & \multirow{2}{*}{$0.13-84.07$} & \multirow{2}{*}{0.27} \\
\hline & $\mathrm{T}$ & 174 & 194 & & & \\
\hline \multirow[t]{2}{*}{ ATP6 G8701A } & G & 120 & 151 & \multirow{2}{*}{0.713} & \multirow{2}{*}{$0.43-1.15$} & \multirow{2}{*}{0.84} \\
\hline & A & 34 & 60 & & & \\
\hline
\end{tabular}


a protective effect. No association of this variant with PD has also been reported in an English population $[1,23]$ and in a Spanish population [9]. A meta-analysis, carried out by Simon et al. [33] revealed this polymorphism tends to associate with PD, but this association was not statistically significant ( $p=0.07$ ). Interestingly, in the present study, the variant tRNAGln 4336T was uncommon in the Mexican mestizo population; there was no association between the 4336T variant and PD. In a previous study of our group, it was also found that there was a low prevalence of p.Gly2019Ser of LRRK2 in the Mexican mestizo population [8]. In contrast, populations of North African Arabs (NA) and Ashkenazi Jews (AJ) have a high frequency and penetrance of the LRRK2 p.Gly2019Ser [14]. In these populations, the mitochondrial haplogroup $\mathrm{H}$, which carries the allele m.4336T>C, is also common [7].

The A8701A/G variant of mtAPT 6 has been associated with variations in the proton gradient across the mitochondrial membrane and with increased levels of calcium, which contributes to neuronal death [17]. In vitro studies have shown that cells carrying the $10398 \mathrm{G}$ allele have higher mitochondrial respiratory chain complex I activity with a protective effect on PD devolvement [37]. In this regard, it has been reported that cell cybrids carrying the $10398 \mathrm{G}$ allele of the MT-ND3 gene and the 8701G allele of the MT-ATP6 gene have higher efficiency energy production and calcium is maintained in homeostasis [14].

However, variant A8701A/G of the MT-APT6 gene is not associated with PD in our study population. Conversely, the A10398G and the two haplotypes that are coupled with 10398A or $10398 \mathrm{G}$ are closely associated with susceptibility to PD in a northern Chinese population [4].

To our knowledge, this is the first work that explores the prevalence of pathogenic variants in tRNAGIn T4336C and ATP6 G8701A genes in the Mexican mestizo population. In the Mexican mestizo population, these variants were not associated with PD. Although these two common pathogenic variants were scarce in the studied population, changes in other nucleotides with similar biochemical properties cannot be excluded. Consequently, it is relevant to continue with the search for specific pathogenic variants of our population, in different genes of mtDNA and other genes related to diseases, such as SNCA, MAO-B and COMT [36]. These types of investigations will elucidate genetic risk factors enabling genetic counseling and potentially discovering new therapeutic targets for PD.

\section{Acknowledgments}

This project was financed by the E-015 institutional program (ISSSTE).

\section{Disclosure}

The authors report no conflict of interest.

\section{References}

1. Bandmann O, Sweeney MG, Daniel SE, Marsden CD, Wood NW. Mitochondrial DNA polymorphisms in pathologically proven Parkinson's disease. J Neurol 1997; 244: 262-265.

2. Benitez BA, Forero DA, Arboleda GH, Granados LA, Yunis JJ, Fernandez W, Arboleda H. Exploration of genetic susceptibility factors for Parkinson's disease in a South American sample. J Genet 2010; 89: 229-232.

3. Biskup S, Moore DJ. Detrimental deletions: mitochondria, aging and Parkinson's disease. Bioessays 2006; 28: 963-967.

4. Chu Q, Luo X, Zhan X, Ren Y, Pang H. Female genetic distribution bias in mitochondrial genome observed in Parkinson's disease patients in northern China. Sci Rep 2015; 5: 17170.

5. Collier TJ, Kanaan NM, Kordower JH. Aging and Parkinson's disease: Different sides of the same coin? Mov Disord 2017; 32: 983-990.

6. Egensperger R, Kösel S, Schnopp NM, Mehraein P, Graeber MB. Association of the mitochondrial tRNA (A4336G) mutation with Alzheimer's and Parkinson's diseases. Neuropathol Appl Neurobiol 1997; 23: 315-321.

7. Feder J, Ovadia O, Blech I, Cohen J, Wainstein J, Harman-Boehm I, Glaser B, Mishmar D. Parental diabetes status reveals association of mitochondrial DNA haplogroup J1 with type 2 diabetes. BMC Med Genet 2009; 10: 60.

8. García S, López-Hernández LB, Suarez-Cuenca JA, Solano-Rojas M, Gallegos-Arreola MP, Gama-Moreno O, Valdez-Anguiano P, Canto P, Dávila-Maldonado L, Cuevas-García CF, Coral-Vázquez RM. Low prevalence of most frequent pathogenic variants of six PARK genes in sporadic Parkinson's disease. Folia Neuropathol 2014; 52: 22-29.

9. García-Lozano JR, Mir P, Alberca R, Aguilera I, Gil Néciga E, Fernández-López O, Cayuela A, Núñez-Roldan A. Mitochondrial DNA A4336G mutation in Alzheimer' and Parkinson's diseases. Eur Neurol 2002; 48: 34-36.

10. González-Vioque E, Bornstein B, Gallardo ME, Fernández-Moreno MÁ, Garesse R. The pathogenicity scoring system for mitochondrial tRNA mutations revisited. Mol Genet Genomic Med 2014; 2: 107-114

11. Gu M, Cooper JM, Taanman JW, Schapira AH. Mitochondrial DNA transmission of the mitochondrial defect in Parkinson's disease. Ann Neurol 1998; 44: 177-186.

12. Gustincich S, Manfioletti G, Del Sal G, Schneider C, Carninci P. A fast method for high-quality genomic DNA extraction from whole human blood. Biotechniques 1991; 11: 298-302. 
13. He ZF, Zheng LC, Xie DY, Yu SS, Zhao J. Mutational analysis of mitochondrial tRNA genes in patients with lung cancer. Balkan J Med Genet 2017; 19: 45-50.

14. Healy DG, Falchi M, O'Sullivan SS, Bonifati V, Durr A, Bressman S, Brice A, Aasly J, Zabetian CP, Goldwurm S, Ferreira JJ, Tolosa E, Kay DM, Klein C, Williams DR, Marras C, Lang AE, Wszolek ZK, Berciano J, Schapira AH, Lynch T, Bhatia KP, Gasser T, Lees AJ, Wood NW. International LRRK2 Consortium. Phenotype, genotype, and worldwide genetic penetrance of LRRK2-associated Parkinson's disease: a case-control study. Lancet Neurol 2008; 7: 583-590.

15. Healy DG, Wood NW, Schapira AH. Test for LRRK2 mutations in patients with Parkinson's disease. Pract Neurol 2008; 8: 381 385.

16. Hughes AJ, Daniel SE, Ben-Shlomo Y, Lees AJ. The accuracy of diagnosis of parkinsonian syndromes in a specialist movement disorder service. Brain 2002; 125: 861-870.

17. Kazuno A Munakata K, Nagai T, Shimozono S, Tanaka M, Yoneda M, Kato N, Miyawaki A, Kato T. Identification of mitochondrial DNA polymorphisms that alter mitochondrial matrix $\mathrm{pH}$ and intracellular calcium dynamics. PLoS Genet 2006; 2: e128.

18. Kochanski A. Pathogenic mutations and non-pathogenic DNA polymorphisms in the most common neurodegenerative disorders. Folia Neuropathol 2007; 45: 164-169.

19. Lin MT, Cantuti-Castelvetri I, Zheng K, Jackson KE, Tan YB, Arzberger T, Lees AJ, Betensky RA, Beal MF, Simon DK. Somatic mitochondrial DNA mutations in early Parkinson and incidental Lewy body disease. Ann Neurol 2012; 71: 850-854.

20. Liu JP. Molecular mechanisms of aging and related diseases. Clin Exp Pharmacol Physiol 2014; 41: 445-458.

21. Luo Y, Hoffer A, Hoffer B, Qi X. Mitochondria: a therapeutic target for Parkinson's disease? Int J Mol Sci 2015; 16: 20704 20730

22. Martinez HR, González-González H, Cantú-Martínez L, Rangel-Guerra R, Hernández-Castillo CD, Vergara-Saavedra J, Ramos-Gonzalez MR, Cerda-Flores RM, Morales-Garza MA, Guerrero-Muñoz MJ, Montes-de-Oca-Luna R, Saucedo-Cárdenas O. PARKIN-coding polymorphisms are not associated with Parkinson's disease in a population from northeastern Mexico. Neurosci Lett 2010; 468: 264-266.

23. Mayr-Wohlfart U, Rödel G, Henneberg A. Mitochondrial tRNA(GIn) and tRNA(Thr) gene variants in Parkinson's disease. Eur J Med Res 1997; 2: 111-113.

24. Mitchell AL, Elson JL, Howell N, Taylor RW, Turnbull DM Sequence variation in mitochondrial complex I genes: mutation or polymorphism? J Med Genet 2006; 43: 175-179.

25. Otaegui D, Paisán C, Sáenz A, Martí I, Ribate M, Martí-Massó JF, Pérez-Tur J, López de Munain A. Mitochondrial polymorphisms in Parkinson's disease. Neurosci Lett 2004; 370: 171-174.

26. Parkinson GM, Dayas CV, Smith DW. Increased mitochondrial DNA deletions in substantia nigra dopamine neurons of the aged rat. Curr Aging Sci 2014; 7: 155-160.

27. Phillipson OT. Management of the aging risk factor for Parkinson's disease. Neurobiol Aging 2014; 35: 847-857.

28. Ramirez-Jirano LJ, Ruiz-Sandoval JL, Jimenez-Gil FJ, RamirezVega J, Vargas-Frutos E, Gallegos-Arreola MP. Frequency of the IVS4+66A-G polymorphism in the alpha-synuclein gene in patients with Parkinson's disease in north-western Mexico. Rev Neurol 2007; 44: 15-17.

29. Rubi-Castellanos R, Martinez-Cortes G, Munoz-Valle JF, Gonzalez-Martin A, Cerda-Flores RM, Anaya-Palafox M, Rangel-Villalobos $\mathrm{H}$. Pre-Hispanic Mesoamerican demography approximates the present-day ancestry of Mestizos throughout the territory of Mexico. Am J Phys Anthropol 2009; 139: 284-294.

30. Sanders LH, McCoy J, Hu X, Mastroberardino PG, Dickinson B, Chang CJ, Chu CT, Van Houte, B, Greenamyre JT. Mitochondrial DNA damage: molecular marker of vulnerable nigral neurons in Parkinson's disease. Neurobiol Dis 2014; 70: 214-223.

31. Santos-Garcia D, Abella-Corral J, Aneiros-Diaz A, SantosCanelles H, Llaneza-Gonzalez MA, Macias-Arribi M. Pain in Parkinson's disease: prevalence, characteristics, associated factors, and relation with other non-motor symptoms, quality of life, autonomy, and caregiver burden. Rev Neurol 2011; 52: 385-393.

32. Schapira AH, Cooper JM, Dexter D, Clark JB, Janer P, Marsden CB. Mitochondrial complex I deficiency in Parkinson's disease. J Neurochem 1990; 54: 823-827.

33. Simon DK, Mayeux R, Marder K, Kowall NW, Beal MF, Johns DR. Mitochondrial DNA mutations in complex I and tRNA genes in Parkinson's disease. Neurology 2000; 54: 703-709.

34. Swerdlow RH, Weaver B, Grawey A, Wenger C, Freed E, Worrall BB. Complex I polymorphisms, bigenomic heterogeneity, and family history in Virginians with Parkinson's disease. J Neurol Sci 2006; 247: 224-230.

35. Tan EK, Chai A, Zhao Y, Lum SY, Fook-Chong SM, Teoh ML, Yih Y, Pavanni R, Wong MC. Mitochondrial complex I polymorphism and cigarette smoking in Parkinson's disease. Neurology 2002; 59: 1288-1289.

36. Torkaman-Boutorabi A, Ali Shahidi G, Choopani S, Reza Zarrindast $M$. Association of monoamine oxidase $B$ and catechol-O-methyltransferase polymorphisms with sporadic Parkinson's disease in an Iranian population. Folia Neuropathol 2012; 50: 382-389.

37. van der Walt JM, Nicodemus KK, Martin ER, Scott WK, Nance MA, Watts RL, Hubble JP, Haines JL, Koller WC, Lyons K, Pahwa R, Stern MB, Colcher A, Hiner BC, Jankovic J, Ondo WG, Allen FH Jr, Goetz CG, Small GW, Mastaglia F, Stajich JM, McLaurin AC, Middleton LT, Scott BL, Schmechel DE, Pericak-Vance MA, Vance JM. Mitochondrial polymorphisms significantly reduce the risk of Parkinson disease. Am J Hum Genet 2003; 72: 804-811.

38. Wang WF, Li X, Guo MZ, Chen JD, Yang YS, Peng LH, Wang YH, Zhang CY, Li HH. Mitochondrial ATP 6 and 8 polymorphisms in irritable bowel syndrome with diarrhea. World J Gastroenterol 2013; 19: 3847-3853.

39. Yescas P, Lopez M, Monroy N, Boll MC, Rodriguez-Violante M, Rodriguez U, Ochoa A, Alonso ME. Low frequency of common LRRK2 mutations in Mexican patients with Parkinson's disease. Neurosci Lett 2010; 485: 79-82. 